\title{
The Effects of Marine Microplastics on Marine Life and Human Health in the Bay of Bengal
}

\author{
Reyhan Sinha ${ }^{1}$ and Michelle Wilson ${ }^{1}$
}

${ }^{1}$ The University of Texas at Dallas, TX, USA

DOI: https://doi.org/10.47611/jsr.v10i1.1131

\begin{abstract}
$\underline{\text { ABSTRACT }}$
Marine microplastics are an emerging pollutant that has already shown adverse effects in fish, mice, and other lowerorder organisms. Based on the impact microplastics have on these organisms, human health will likely be affected, especially in areas where fish and other marine life are a significant part of the diet. A wide range of previously conducted research was used to study the effects and predict the dangers of microplastic consumption on human health. The sources covered three general topics: the effects of microplastics on commonly consumed European and Mediterranean fish, their effects on the gut microbiome of mice, and the transmission of microplastics across trophic levels. A prediction was made using the presented data, stating that there will be and there is already a likely effect on the human neuroendocrine and digestive systems. This assumption was drawn from the known health effects of microplastics on fish and mice and the processes of bioaccumulation and biomagnification. In conclusion, it was predicted that the regular consumption of contaminated fish is likely already affecting human health in the region. Furthermore, the current policies and regulations focused on plastic pollution in India and Bangladesh are either not strong enough or not enforced well enough to reduce the amount of plastic pollution in the bodies of water in the region.
\end{abstract}

\section{Introduction}

Few materials have been as important to humanity as plastics. First developed in the 1800s, plastics are now used in almost every industry with various uses, ranging from food, medical, and industrial applications. However, this is not without significant pollution issues, and in recent years the focus on plastic pollution has increased. Plastics make up a significant amount of global pollution, and more specifically, marine pollution. One of the most significant issues in marine pollution is microplastics. Microplastics are plastic particles that are less than $5 \mathrm{~mm}$ in size 1 and occur in two types. Primary microplastics are pieces that are already $5 \mathrm{~mm}$ or smaller when they enter the environment (microbeads, clothing microfibers, packaging, etc.)2, while secondary microplastics are plastic pieces that are eroded or degraded from larger items such as plastic bags and other large items2. The microplastic particles can have physical effects on sea life, such as blockage of digestive and airway passages and the potential to act as a pathogen vector. Additionally, microplastic particles pose a chemical hazard to the fish that ingest them due to the compounds utilized during synthesis. These particles can be hazardous to fish in these environments and to people who eat these fish (such as sea bass and carp) due to the chemical and physical effects on the human body. For example, those who consume fish caught from the Ganges River and the Bay of Bengal are eating organisms from one of the most plastic polluted areas on the planet. Based on research into the effects of plastics on marine life and mice, there is a high likelihood that microplastics will cause some manner of health effects on the human body, but at present, the actual damage is unknown. 


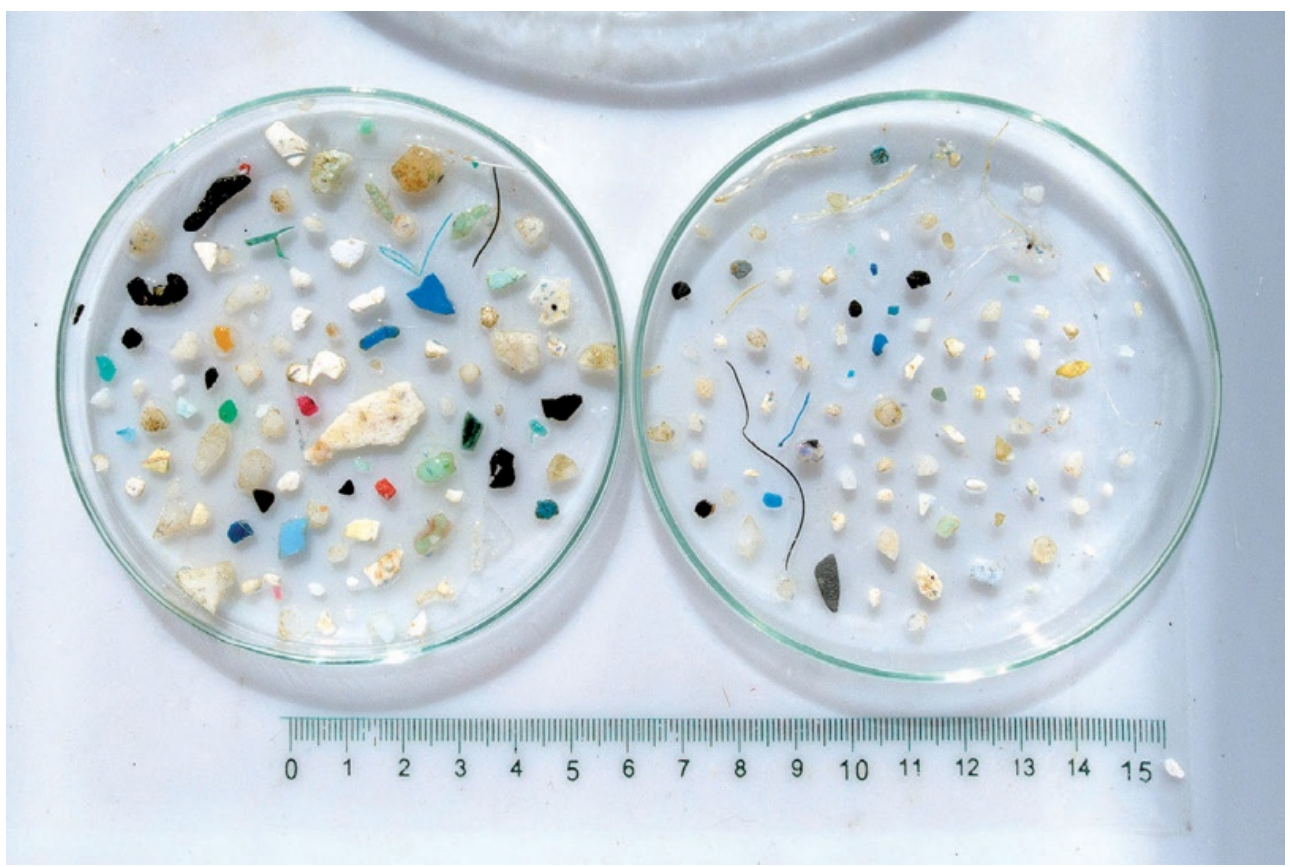

Figure 1: Microplastic sediments recovered from the Pacific Ocean. Photo credit to Samuel Bollendorff

Microplastics can be dangerous in a few different ways. The two general methods of danger are physical and chemical. The chemical dangers of microplastics can be shown when looking at the process of plastic creation/synthesis1,24. At its core, plastics are just polymers, made up of thousands of carbon chains with other atoms; usually, oxygen, hydrogen, nitrogen, or sulfur, added to them. Each carbon unit (a carbon atom with bonds to other atoms) is known as a monomer, and the whole chain is the polymer. While each type of plastic has unique requirements for synthesis, the underlying process is the same throughout. The first precursor is refined from a crude hydrocarbon, further purified into the desired monomer, and then polymerized to form the final product. The type of plastic is determined by looking at the functional group's name after the poly-prefix, hence the names such as polyethylene, polycarbonate, polyamide.

For example, in the production of polyethylene, the precursor of this polymer is a hydrocarbon derived from crude oil. Crude oil contains a mix of heavy and light hydrocarbons, which are separated during the refining process. In this case, the terms "heavy" and "light" refer to the hydrocarbons' molecular weight. The refining process utilizes a method known as fractional distillation, where the hydrocarbons are separated based on their respective boiling points, which are determined by their molecular weight. 


\section{Crude oil distillation unit and products}

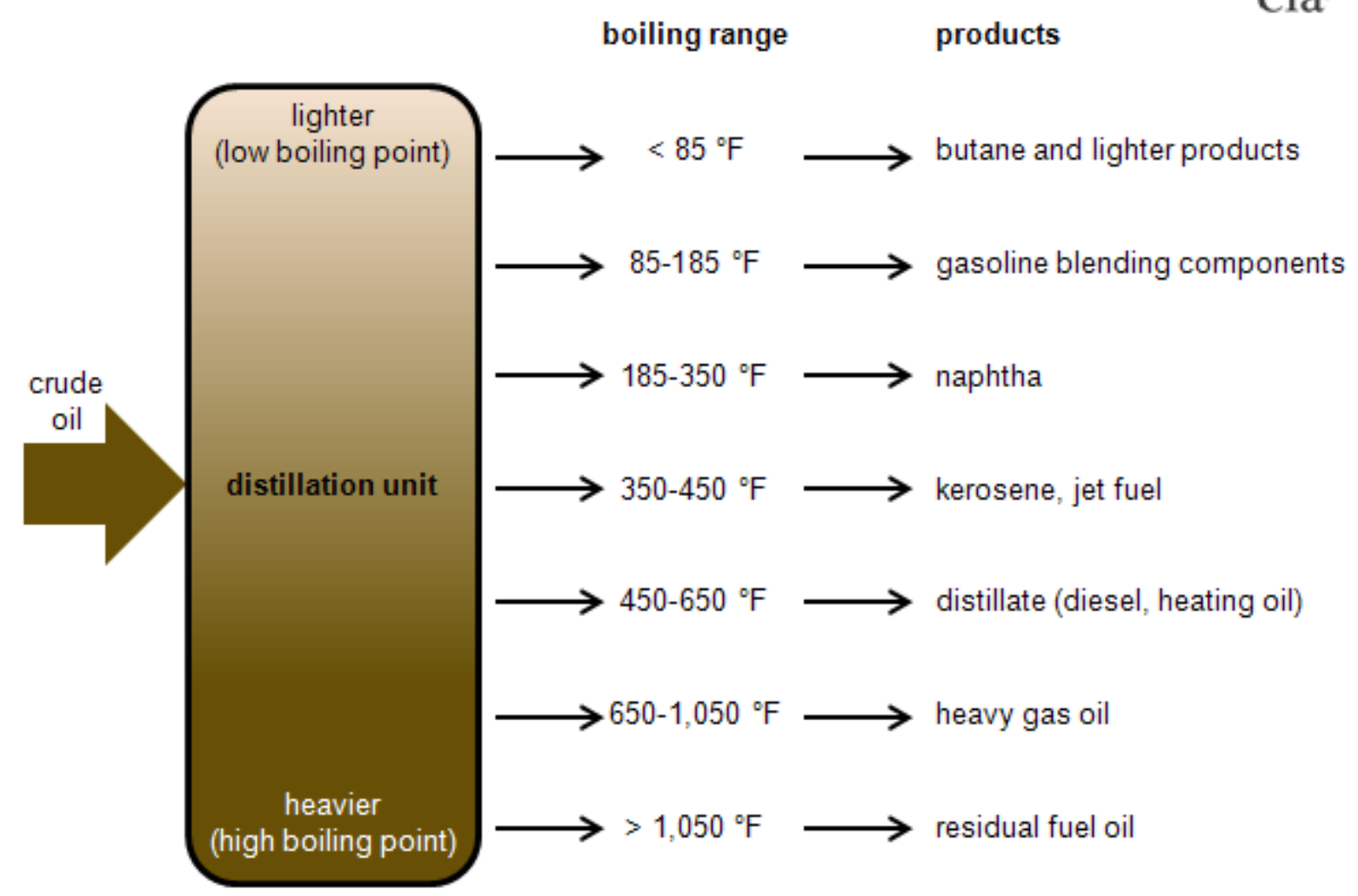

Figure 2: Process of crude oil distillation. Credit to the U.S. Energy Information Administration

As shown in Figure 2, simpler compounds such as propane and butane are derived from the lightest fractions, while more complex compounds such as tar and wax are synthesized from the heavier hydrocarbons. The compounds in the middle of the weight range become fuels such as petroleum, jet fuel, and kerosene. The petrochemical feedstocks used to synthesize plastics originate from these compounds. One such feedstock is a compound known as naphtha ${ }^{38}$, which is broken down further in a process known as steam cracking. Steam cracking breaks down saturated hydrocarbons into smaller unsaturated forms. In naphtha's case, these are the light alkenes, ethylene, or propylene. While this process has fallen out of use in the U.S., it is still widely used in Europe and Asia. Once purified, the ethylene will be polymerized $^{5}$ using a combination of high heat and high pressure with a free radical catalyst and is used to create a very low density and flexible form of plastic known as low-density polyethylene (LDPE) ${ }^{1}$. The creation of stronger compounds such as high-density polyethylene (HDPE) is achieved by utilizing titanium or chromium catalysts under low temperature and pressure. This finished product is the plastic resin, which still needs to be shaped and molded into the final product. The molding process involves another group of compounds known as plasticizers. Plasticizers are compounds such as Bis(2-ethylhexyl) phthalate (DEHP), and they are used to decrease the plasticity (the ability for a material to be deformed) and viscosity (the "thickness" of a liquid). They are an integral part of the plastic production process as they allow the finished product to be physically reshaped into the desired shape. The chemicals mentioned above are known hazardous organic pollutants and animal carcinogens which have a known effect on human health by acting as endocrine disruptors.

The human endocrine system contains several endocrine glands such as the pituitary gland, thyroid, and adrenal glands that secrete signaling molecules, known as hormones, that travel throughout the body to affect the target organ's function. Compounds such as DEHP and Bisphenol-A (BPA) are known as endocrine disruptors, and they work by acting as a chemical antagonist/analog for the hormones in the endocrine system. By mimicking the structure of hormones such as estrogen or testosterone, they can inhibit normal function when at a high enough 
concentration. BPA is one of the most notorious chemicals in this regard; it is a known competitive estrogen inhibitor while also causing tissue damage to the nervous, immune, and reproductive systems. Regulations to end BPA usage have been implemented in the past few decades, but a recent study has found that most plastic products release some form of an estrogen analog39. From the above information, a significant number of chemicals utilized in plastic production can disrupt the normal function of the endocrine system. Given how interconnected human body systems are, the effects will likely reach beyond just endocrine issues. The microplastics that contaminate the water sources will contain some of these toxic compounds from the production process. Over time, one of two things will occur, either the compound will leech from a plastic particle and enter the water supply, or a fish will consume the plastic containing the compound. As the fish tries to digest the particle, the compound will be absorbed into its body, and when eaten by a human, the compound will be absorbed by epithelial tissue in the digestive system.

\section{The entry into the water supply and effects on the food web:}

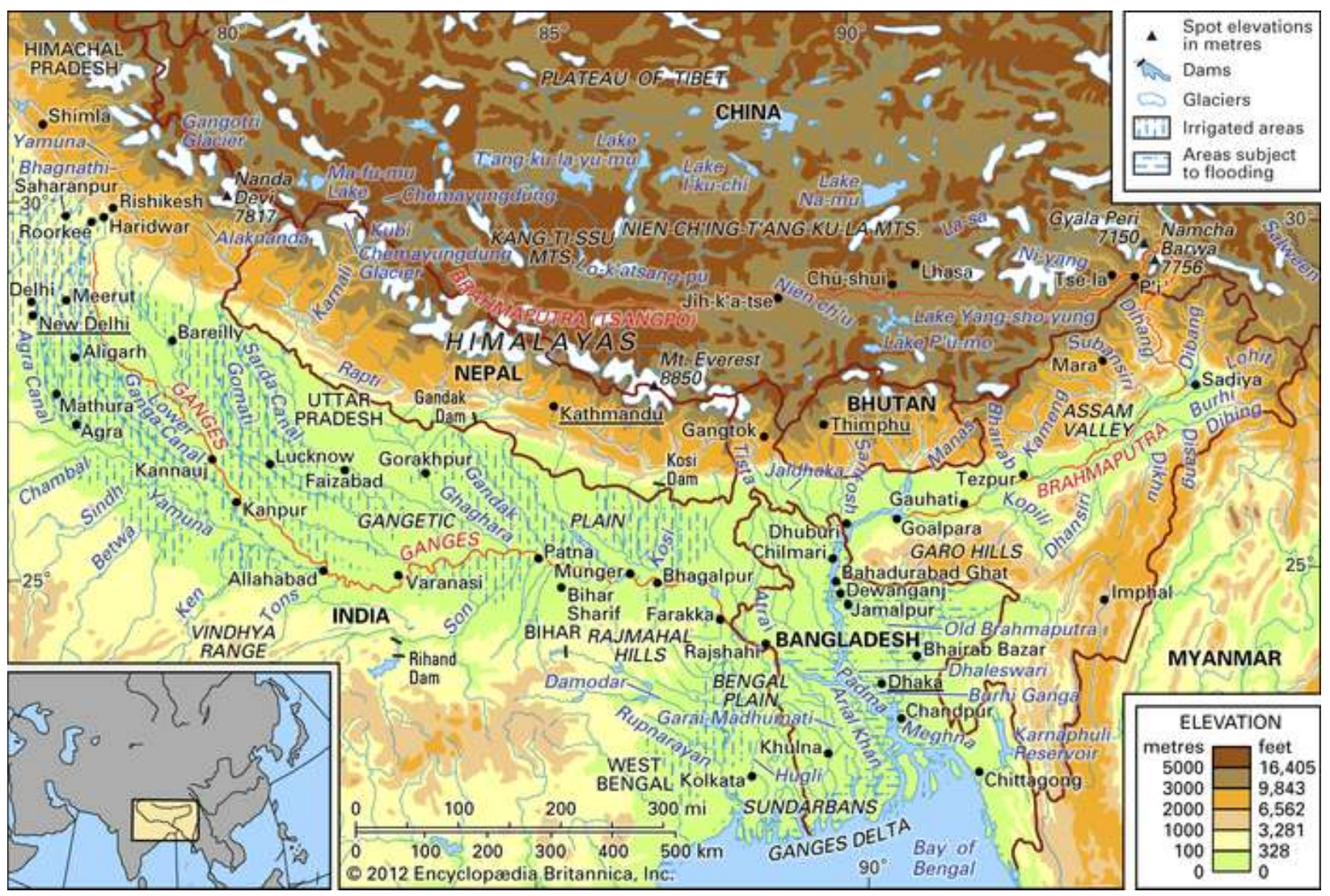

Figure 3 Map of the Ganges River and delta. All credit to Encyclopedia Britannica

Plastic disposal and pollution of coastlines and feeder sources is the primary way that plastics enter the water supply. The plastics that enter this way will be broken down into smaller particles (a secondary microplastic) via U.V. radiation or erosion via water or wind. The breakdown of plastics is a significant problem in the Ganges River, which flows through India and Bangladesh and into the Bay of Bengal. It is one of the most polluted rivers in the world due to two significant factors; the lack of a proper waste management system for the populated areas along the river and the river's significance to Hinduism, where millions make a pilgrimage to it every year.

In these regions, the abundance of low-cost plastics and lack of a proper waste management system has led to the disposal of a significant quantity of plastic waste into open sewers, feeder sources, and the river shores. That combination allows millions of bottles, bags, food packaging, clothing fibers, and other plastic waste forms to enter 
the river and start getting broken down. The other concern is the river's role in Hinduism, where it is viewed as sacred and represents the physical manifestation of the goddess Ganga. Hindus believe that the river's water is purifying, so bathing in the river has a spiritual cleansing effect and forgives them of all their sins. For this reason, millions not only bathe but also offer tributes to the river, with many of these offerings being some plastic artifact. These artifacts are single-use items and will inevitably start breaking down into secondary microplastics. A recent National Geographic study found that around 110,000 tons of plastic are carried by the Ganges river into the Bay of Bengal each year. This amount of plastic poses an immediate health risk to the over 400 million people who rely on the river as a source of drinking water30. Furthermore, the fish in the river will consume the broken-down plastics, which will inevitably be consumed by humans since fish are a dietary staple in the region.

While this paper focuses specifically on plastic pollution in the Ganges, this is a broader critical issue in rivers and coastlines around the world. Regardless of the source, plastics will inevitably get broken down into smaller and smaller pieces and start to contaminate the lowest levels of the food web. While this paper is focused on one geographical region, the general pathway of plastics entering the water supply is similar throughout the world. Improperly disposed plastic waste near bodies of water will slowly be eroded into smaller pieces and, over time, will enter the marine environment. Once here, the effects on the food web begin to take hold. A significant part of how microplastics affect organisms is how these particles move up the food web.

The food web is an ecological representation of how various food chains interact in an environment. The food chain is an organization of species, starting with the lowest organism and ending with an apex predator, where each species preys on the one below it. The major terms that need to be understood here are trophic levels, biomagnification, and bioaccumulation. The trophic level refers to the position an organism has on the food web. The first trophic level contains autotrophic organisms such as plants and algae, commonly referred to as producers. The second levels concern organisms that eat those from the first, the third level organism eats the second, and so on. Organisms at the top of the web are known as apex predators. 


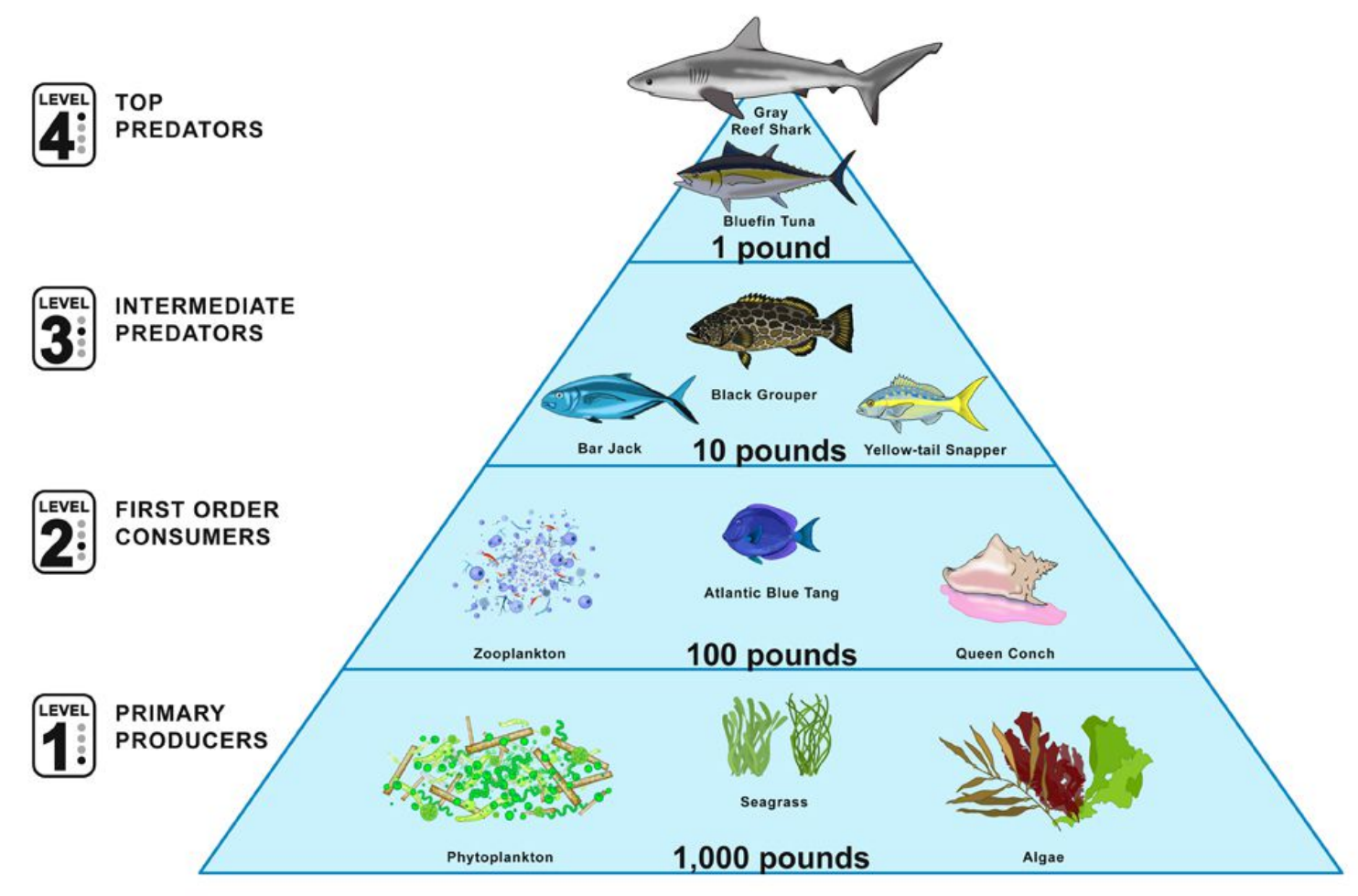

Figure 4: Simplified view of the marine food pyramid. Humans (not depicted) are a level 4 predator from this diagram. Illustration by Tim Gunthe.

For this paper, assume that algae are the first level, organisms such as plankton are the second, fish are the third, and humans are the fourth level. At this point, the process of bioaccumulation and biomagnification comes into play. Bioaccumulation refers to the build-up of a substance within a single trophic level, such as a fish consistently consuming contaminated prey, allowing a build of toxins in its body. Biomagnification refers to the increasing concentration of toxins in organisms higher on the food chain. An example of this is humans regularly consuming contaminated fish that ate contaminated plankton which fed on plastic-contaminated algae. These basic ecological principles begin to show the magnitude of the problem that microplastics can create. As soon as plastics contaminate the first trophic level, the damage is done. The contaminants will build-up, and the effects will amplify as the resources move up the food chain, which poses a significant risk for humans.

\section{Human consumption of fish}

Modern archeological and anthropological studies have shown that early groups of humans followed the coasts while leaving Africa. Studies have shown that humans have been consuming fish for at least the past 40,000 years. These studies have found artifacts thought to be early forms of fishhooks and fishing nets worldwide. Ever since, seafood has featured prominently in ancient Israeli, Roman, Chinese, Japanese, and Indigenous American diets. Since this paper focuses on the effects of marine microplastics on Bengali populations, one needs to understand the cultural reasons behind fish consumption in the region. The region contains the Indian State of West Bengal (majority Hindu) and the nation of Bangladesh (majority Muslim). Due to the region's location on the Bay of Bengal and containing the two major branches of the Ganges River, as well as the Ganges Delta in Bangladesh, both fresh and saltwater fish are 
highly abundant in the region. While fish do not have a significant religious connection to Hinduism or Islam, fish plays a prominent role in both Bengali Hindu and Muslim traditions, such as weddings, the birth of a child, and in orthodox Hinduism, a symbol of a mourning widow. Additionally, fish is a critical part of the region's diet, with fish consumed daily during one meal and served as the main protein source. Fish only make up a small part of the meal, but a nutritionally important one, nonetheless.

Dietary fish provide a significant source of lean protein and is a significant source of omega-3 fatty acids, which studies have shown to provide cardiovascular and brain health benefits. Additionally, fish consumption is beneficial in the acquisition of Vitamins D and B240, essential amino acids, and minerals such as zinc, iron, magnesium, potassium, and iodine. All the vitamins and minerals mentioned have a critical role in essential biological functions such as cellular respiration, maintaining red blood cell count, mineral absorption, and bone health. The nutritional benefits mentioned above show the need for fish to be included in any balanced diet and highlight the potential issues to humans caused by consumption of fish with a build-up of microplastics. The effects of bioaccumulation and biomagnification can cause serious health issues in humans, especially in areas such as West Bengal and Bangladesh, where fish make up a critical part of the diet.

All of the topics explored here help to explain how microplastics have adverse physical and chemical effects on the organisms that inadvertently consume them. A model can now be created using the understanding of the physical, chemical, and ecological effects of plastics and cultural aspects of humans who rely on fish as a dietary staple, specifically those in the Bay of Bengal, demonstrating humans in regions of water contaminated plastics will likely suffer from health effects due to the consumption of microplastic-contaminated fish.

\section{Analysis}

Utilizing the aforementioned research and information, a prediction can be made that the populations that consume fish from the Ganges River and its tributaries and from the Bay of Bengal will have a higher incidence of digestive and endocrine issues from microplastic toxicity. Research conducted over the past ten years has shown how microplastics have detrimental effects on brain health, behavior, gut flora composition, and how microplastics build up in the tissues of the organisms that consume them. Using the previously published research about the accumulation of plastics in marine life will aid in the creation of the model to show how build-up will have an effect on human health. Additionally, all fish have the same basic underlying body systems and biochemical pathways, many of which have analogs in the human body that will further aid in creating the model.

Research into the effects of microplastics on European sea bass (Dicentrarchus labrax) 4 and Mediterranean rabbitfish (Siganus rivulatus)14 have shown several physiological effects, including but not limited to plastic buildup in soft tissue, altered behavior, as well as brain and muscle damage in D. labrax. While the biological effects will differ due to the specifics of each species, the general pathway of toxin and particulate accumulation will be across all species. A toxicology study conducted in European sea bass, a popular dietary fish, showed conclusive results that microplastic accumulation resulted in neurotoxicity, oxidative-damage, and interfered with the organism's energy production. While this study was specifically looking at how mercury bioaccumulation occurs through microplastics, results were also shown from what happened when just microplastics were consumed during normal feeding. The study found that ingestion microplastics inhibited the normal function of acetylcholinesterase (AChE). The primary function of $\mathrm{AChE}$ is to break down the neurotransmitter acetylcholine, which has several critical functions, including muscle contraction, vasodilation, and functions of the autonomic nervous system. Additional biochemical effects on D. Labrax included lipid oxidation in muscle and brain tissue. Oxidation of these tissues is a sign that the tissues are starting to break down. Furthermore, a drop in levels of isocitrate dehydrogenase (IDH) activity and a rise in lactate dehydrogenase (LDH) levels were detected. The function of LDH is to convert NAD+ into NADH and back, which catalyzes the conversion of pyruvate to lactate and the reverse. It is expressed in many human body tissues and expressed in elevated levels in damaged tissue. IDH catalyzes the oxidative decarboxylation of isocitrate into alphaketoglutarate in the TCA cycle, a crucial step in cellular respiration and generation of ATP in the mitochondria. In 
short, when looking at a high microplastic concentration, the study showed a steep increase in LDH activity, a sharp drop in IDH activity, and a sharp decrease in AChE activity in the brain of the fish that consumed the microplastics at a sufficiently high concentration3. The effect on these enzymes in fish has implications for human health as all of the enzymes mentioned above are present in the human body. These results have been backed up by similar findings from wild fish consumed by humans from the North-East Atlantic Ocean3. Similarly, a study of rabbitfish in the Mediterranean Sea confirmed that polychlorinated biphenyls (PCBs), a type of plasticizer, were delivered via a microplastic vector. Further research found PCBs in the muscles14. The muscles make up a large part of the fish meat consumed by humans, and given that microplastics, mercury, and PCBs were found in some consumed fish via the microplastic vector, an assumption can be made that the compounds mentioned above would be absorbed into the human body after consumption. It was speculated that this would result in long-term harm to the fish and possibly predators and humans that consume them. This prediction can be made since PCBs were a commonly used plasticizer until the late 1970s, when research into the environmental effects became apparent. Like many plasticizers, PCBs have been shown to be endocrine disruptors, animal carcinogens, and probable human carcinogens 36 . Based on the research done so far in the European, Mediterranean, and North Atlantic fish, an assumption can be made that a similar process is occurring in common Bengali dietary fish such as Rohu (Labeo rohita) and Ilish (Tenualosa ilisha). Like most fish, they feed on plankton; if the plankton is contaminated with plastic, the plastics will begin accumulating in the fish. Over time this will cause damage to the brain and affect the behavior of the fish.

The idea of plastics moving up the food chain and harming the fish that consumed them was explored in a paper by Mattsson et al.22 in 2017. That study showed that plastics delivered through the food chain could cause brain damage and behavioral changes in fish. The study looked at the transmission of nanoplastics (smaller plastic particles, $1 \mu \mathrm{m}$ or less in size) through the food chain and found that plastic concentration in Daphina magna (zooplankton) affected both the survival of the organism, as well as effects in the fish that consume them. The study first looked at the effect of increasing concentrations of polystyrene nanoparticles on the plankton. By studying the effect on plankton from plastic concentrations ranging from $0.025 \mathrm{~g} / \mathrm{L}$ to greater than $0.075 \mathrm{~g} / \mathrm{L}$, they determined that the particle concentration was the crucial factor in the level of toxicity. The link between the two was demonstrated by showing that plankton exposed to plastic concentrations greater than $0.075 \mathrm{~g} / \mathrm{L}$ were dead in less than a day. Based on these findings, a study of the effects on the food chain was done, which found a direct connection between the plastics and damage to brain tissue in fish. Specifically, the plastics were shown to penetrate the blood-brain barrier in fish and cause behavioral changes. These changes include their overall activity levels and feeding time. More importantly, the study showed proof that plastic particles can move up the food chain and cause physiological damage at every level. This idea can be extended to edible bivalves as well. A 2014 study over microplastic accumulation in edible bivalves6 analyzed the ingestion of microplastics into two types of edible shellfish, Mytilus edulis and Crassostrea gigas. The results of the experiment showed a small amount of microplastic in the soft tissue of these organisms. Bivalves are a popular food source for coastal populations and have many predators, such as the common carp (Cyprinus carpio) that are popular human food sources, especially in Asia. This brings back the idea of the contamination of the food web discussed earlier.

While this paper's primary focus is on marine microplastics, information from a parallel study about the potential effects of microplastics on the gut microbiome, especially in overexposed species, can help to back up the model being generated. The human gut microbiome refers to the millions of microorganisms that reside in the digestive tract. These bacteria are highly beneficial and maintain a mutualistic relationship with their human host. They have been shown to assist in digestion, immune response, and pathogenesis. Studies into gut dysbiosis (microbial imbalance of gut bacteria) have a connection between changes in gut flora and an increased risk of chronic diseases and infections8. In Western countries, modern diets and antibiotic use have been implicated in the extinction of certain strains of gut flora. Additionally, the ingestion of microplastics has been theorized as another cause of this extinction. The theory has been backed up by several recent studies of microplastics' effect in mice and the resulting changes in their gut microbiomes. This study exposed male mice to $5 \mu \mathrm{m}$ polystyrene microplastics for six weeks and studied the effects on the gut barrier, flora, and metabolism. The results from plastic accumulation showed that the plastics caused amino 
acid and bile metabolism disorders, induced gut bacteria dysbiosis, and intestinal barrier dysfunction in relation to the control group. Another study concerning polystyrene microplastics in mice produced similar results, where lipid metabolism and intestinal mucous secretion were decreased and gut bacteria dysbiosis was increased. These results are alarming as mice share a number of biological similarities to humans. It begs the question, if this has already been shown to happen in mice, what is happening to humans? The mechanical disruptions to the digestive system are a particularly troubling thought. The intestinal epithelium is joined together by a complex set of desmosomes, tight, gap, and adherens junctions. Their function is to absorb nutrients while preventing pathogens, foreign particles, and other unwanted molecules from entering the bloodstream. This lining is one of the first defenses against pathogens and bacterial translocation into the bloodstream, so any tears, abrasions, or cuts in this lining open up the bloodstream to the pathogens or toxic compounds in/on them. Once they have entered the bloodstream, the endocrine-disrupting compounds involved in the production process can begin their disruptive functions.

Since pollution levels in the Mediterranean Sea and North Atlantic are lower than the pollution levels in the Bay of Bengal, it raises the focus of the effect microplastics are having, the severity of the issue, and human health in the Bay of Bengal. Based on the biomagnification principle as well as studying pollution levels in the Bay of Bengal and Ganges River, it can be assumed that those who eat a diet primarily consisting of fish, especially from heavily polluted areas, will be at high risk for issues caused by the build-up of these toxins in the food web. At this point, this is only a prediction since very little research has been conducted on the effects of microplastic ingestion on human health. Most of the research has been conducted on mice and marine life, such as fish, plankton, and bivalves. However, based on the research conducted, it is clear that the question of microplastic contamination of marine food sources will affect human health. The question is a matter of when, not if. The studies on the North Atlantic fish have shown the effects of the particles on AChE, LHD, and IDH, all of which are critical enzymes in human biochemistry. Plastic sediment was also found in shellfish cultivated for humans, and research has shown that microplastic build-up can cause mechanical, chemical, and pathogenic disruptions in the organisms that consume them, as well as the gut microbes of those organisms. While the magnitude of damage to humans cannot be measured yet, it can be said with certainty that at the current rate of microplastic exposure, damage to the human body will occur. Further studies in coastal areas, particularly the Ganges and Bay of Bengal region, need to be conducted to understand the levels of microplastic contamination along with mechanical, chemical, and pathogenic effects of microplastics in the region.

A hypothetical pathway can now be formed, where a single-use plastic bottle is produced, sold, used, and then trashed. However, due to the lack of proper plastic waste disposal infrastructure in the region, the bottle ends up in the Ganges, broken down by a mixture of tidal currents, U.V. radiation, and wind erosion. The particles from the broken-down bottle can now contaminate the algae, plankton, and other food sources for mid-level prey. The plastic will affect the prey and begin to affect the predators, as shown in previously published research. The effects are exacerbated as the fish eats during its lifespan until it is caught by a fisherman and sold. It is now eaten as part of a standard Bengali meal, something that is eaten on most days. The plastic and chemical toxins from it the fish will then be transferred to the human as it is digested and absorbed into the human's intestinal epithelial lining. Given the known biological effects of fish and looking at the similarities between fish and human biochemistry, the toxins in plastics will begin to take their toll on the region's human population, especially as more and more fish is consumed.

\section{Conclusion}

Regulations on plastic production and waste management in the United States and European Union have been in place for a few decades but developing nations such as India and Bangladesh still lags behind in the regulation of toxic compounds such as BPA, DEHP have been catching up to cut fight the effects of plastic pollution, it may be too little, too late. While both India and Bangladesh have attempted to regulate single-use plastics in recent years, there have been issues with enforcement. In Bangladesh, the nation's High Court ordered the government to implement a ban on single-use plastics. This step has the potential to decrease plastic pollution, but the enforcement of the court ruling needs to be watched, as a 2002 ban on plastic bags was not widely enforced. Similarly, in India, the fight against 
plastic pollution is facing mixed results. A proposed ban on single-use plastics in India in August 2019 was scrapped just a few months later, after pushback from the plastics industry. With the lack of a national strategy for plastic pollution mitigation, the various Indian states and major cities have taken up the mantle of combating plastic pollution with varied results. Cities like Mumbai have imposed strict penalties on single-use plastics, while in the state of Assam, the ban goes unenforced. Meanwhile, plastics manufacturing lobbying groups across India have been claiming lost jobs, wages, and profit and are suing to have the bans overturned.

Failures like the ones mentioned above make up a significant issue in the fight to curb plastic pollution. Once the plastic is in the ecosystem, removing them is an arduous process as the plastics being breaking down into secondary microplastics. The best mitigation strategy at this point would involve a multi-step approach with continued studies on human health, clean-up operations continuing and policy changes taking in the latest data from the research conducted. Mitigation efforts to prevent plastics from entering bodies of water should be step one, as it would be the easiest to accomplish first, with relatively quick results. Achieving this would require shifting to bio-degradable products, ending the reliance on single-use plastics where possible, filtering sewage to stop plastics that make it in, and implementing a robust plastic waste disposal infrastructure. Implementing a waste disposal infrastructure would require public education campaigns to teach those in affected areas about the possible health hazards of uncontrolled plastic pollution and making sure the new infrastructure is easy to understand and accessible. At the same time, studies of the direct effects of microplastic ingestion need to be conducted in further detail, focusing on the effects on human health. Studies that could be conducted involve studying the rate of digestive epithelial tissue damage among various population groups living in coastal areas with and without strong plastic production regulations and looking at inland areas with the same conditions. Another study could look at the effect of land-based or airborne microplastics on farm animals such as cattle, chickens, and pigs. An extension of this study could be to look at the effect of soil-based microplastics on staple grains such as wheat and rice. These are just a few examples but given how new the field of microplastic effects on humans is, the avenues for further study are wide open. The final part of the mitigation strategy would fall upon governments and regulators to minimize or outright ban the use of certain compounds in the production process that leads to the toxins seeping into the water supply and affecting marine life. The effects of marine microplastics on populations that consist of a heavily fish-based diet is an important but relatively poorly studied topic. Further research needs to be conducted, and a significant shift in humanity's attitude towards plastic needs to occur to understand and treat the likely health effects from the constant ingestion of microplastics.

\section{References}

1. American Chemistry Council. "How Plastics Are Made." How Plastics Are Made, 2019, plastics.americanchemistry.com/How-Plastics-Are-Made/.

2. Andrady, Anthony L. "The Plastic in Microplastics: A Review." Marine Pollution Bulletin, vol. 119, no. 1, 2017, pp. 12-22., doi:10.1016/j.marpolbul.2017.01.082.

3. Barboza, Luís Gabriel A., et al. "Microplastics in Wild Fish from North East Atlantic Ocean and Its Potential for Causing Neurotoxic Effects, Lipid Oxidative Damage, and Human Health Risks Associated with Ingestion Exposure." Science of The Total Environment, vol. 717, 2020, p. 134625., doi:10.1016/j.scitotenv.2019.134625.

4. Barboza, Luís Gabriel Antão, et al. "Microplastics Cause Neurotoxicity, Oxidative Damage and EnergyRelated Changes and Interact with the Bioaccumulation of Mercury in the European Seabass, Dicentrarchus Labrax (Linnaeus, 1758)." Aquatic Toxicology, vol. 195, 2018, pp. 49-57., doi:10.1016/j.aquatox.2017.12.008. 
5. Bleeke, John R, and Regina F Frey. "Ethylene Polymerization." Session 2, 15 June 2006, www.chemistry.wustl.edu/ edudev/Designer/session2.html.

6. Cauwenberghe, Lisbeth Van, and Colin R. Janssen. "Microplastics in Bivalves Cultured for Human Consumption." Environmental Pollution, vol. 193, 2014, pp. 65-70., doi:10.1016/j.envpol.2014.06.010.

7. Claessens, Michiel, et al. "Occurrence and Distribution of Microplastics in Marine Sediments along the Belgian Coast." Marine Pollution Bulletin, vol. 62, no. 10, 2011, pp. 2199-2204., doi:10.1016/j.marpolbul.2011.06.030.

8. Collard, France, et al. "Microplastics in Livers of European Anchovies ( Engraulis Encrasicolus , L.)." Environmental Pollution, vol. 229, 2017, pp. 1000-1005., doi:10.1016/j.envpol.2017.07.089.

9. Dasgupta, Neha. "India Shelves Plan on Countrywide Ban on Single-Use Plastic Products." Reuters, Thomson Reuters, 2 Oct. 2019, www.reuters.com/article/us-india-pollution-plastic/india-shelves-plan-on-countrywide-ban-on-single-use-plastic-products-idUSKBN1WG43W.

10. Digital Desk, Staff Reporter. "Plastic Ban Turns into a Farce in Assam." The Sentinel, 19 July 2019 , www.sentinelassam.com/top-headlines/plastic-ban-turns-into-a-farce-in-assam/ .

11. Fackelmann, Gloria, and Simone Sommer. "Microplastics and the Gut Microbiome: How Chronically Exposed Species May Suffer from Gut Dysbiosis." Marine Pollution Bulletin, vol. 143, 2019, pp. 193-203., doi:10.1016/j.marpolbul.2019.04.030.

12. Farrell, Paul, and Kathryn Nelson. "Trophic Level Transfer of Microplastic: Mytilus Edulis (L.) to Carcinus Maenas (L.)." Environmental Pollution, vol. 177, 2013, pp. 1-3., doi:10.1016/j.envpol.2013.01.046.

13. "Government of Assam Has Imposed a Complete Ban on Single-Use of Plastics." Government of Assam, 30 Sept. 2019, assam.gov.in/en/mediavideo/Ban\%20on\%20singleuse\%20of\%20plastics.

14. Hal, Noam Van Der, et al. "Uptake and Incorporation of PCBs by Eastern Mediterranean Rabbitfish That Consumed Microplastics." Marine Pollution Bulletin, vol. 150, 2020, p. 110697., doi:10.1016/j.marpolbul.2019.110697.

15. Hu, Y., et al. "Stable Isotope Dietary Analysis of the Tianyuan 1 Early Modern Human." Proceedings of the National Academy of Sciences, vol. 106, no. 27, 2009, pp. 10971-10974., doi:10.1073/pnas.0904826106.

16. Inadera, Hidekuni. "Neurological Effects of Bisphenol A and Its Analogues." International Journal of Medical Sciences, vol. 12, no. 12, 30 Oct. 2015, pp. 926-936., doi:10.7150/ijms.13267.

17. Jin, Yuanxiang, et al. "Impacts of Polystyrene Microplastic on the Gut Barrier, Microbiota and Metabolism of Mice." Science of The Total Environment, vol. 649, 2019, pp. 308-317., doi:10.1016/j.scitotenv.2018.08.353. 
18. Liu, Xuemin, et al. "Microplastics as Both a Sink and a Source of Bisphenol A in the Marine Environment." Environmental Science \& Technology, vol. 53, no. 17, 2019, pp. 10188-10196., doi:10.1021/acs.est.9b02834.

19. Lu, Liang, et al. "Interaction between Microplastics and Microorganism as Well as Gut Microbiota: A Consideration on Environmental Animal and Human Health." Science of The Total Environment, vol. 667, 2019, pp. 94-100., doi:10.1016/j.scitotenv.2019.02.380.

20. Lu, Liang, et al. "Polystyrene Microplastics Induce Gut Microbiota Dysbiosis and Hepatic Lipid Metabolism Disorder in Mice." Science of The Total Environment, vol. 631-632, 2018, pp. 449-458., doi:10.1016/j.scitotenv.2018.03.051.

21. Lwanga, Esperanza Huerta, et al. "Field Evidence for Transfer of Plastic Debris along a Terrestrial Food Chain." Scientific Reports, vol. 7, no. 1, 2017, doi:10.1038/s41598-017-14588-2.

22. Mattsson, Karin, et al. "Brain Damage and Behavioural Disorders in Fish Induced by Plastic Nanoparticles Delivered through the Food Chain." Scientific Reports, vol. 7, no. 1, 2017, doi:10.1038/s41598-017-108130 .

23. Paul, Ruma. "Bangladesh to Ban Use of Single-Use Plastic in Hotels and Restaurants." Reuters, Thomson Reuters, 6 Jan. 2020, www.reuters.com/article/us-bangladesh-environment-plastic/bangladesh-to-ban-useof-single-use-plastic-in-hotels-and-restaurants-idUSKBN1Z51BK.

24. PlasticsEurope. "How Plastics Are Made." PlasticsEurope, 2020, www.plasticseurope.org/en/about-plas$\underline{\text { tics/what-are-plastics/how-plastics-are-made. }}$

25. Prata, Joana Correia. "Airborne Microplastics: Consequences to Human Health?" Environmental Pollution, vol. 234, 2018, pp. 115-126., doi:10.1016/j.envpol.2017.11.043.

26. "Presence of Microplastics and Nanoplastics in Food, with Particular Focus on Seafood." EFSA Journal, vol. 14, no. 6, 2016, doi:10.2903/j.efsa.2016.4501.

27. "Press Corner." European Commission - European Commission, European Commission, May 2019, ec.europa.eu/commission/presscorner/detail/en/IP_19_2631.

28. Rao, B. Madhusudana. "Microplastics in the Aquatic Environment: Implications for Post-Harvest Fish Quality." Indian Journal of Fisheries, vol. 66, no. 1, 2019, doi:10.21077/ijf.2019.66.1.83125-20.

29. Roberts, Joe, and Colleen Taylor Sen. "Fish: Food from the Waters." Fish: Food from the Waters, by Harlan Walker, Prospect Books, 1998, pp. 252-258.

30. Sampathkumar, Yasaswini. "Plastic Bans Spread in India. Winners and Losers Aren't Who You'd Expect." Plastic Bans Spread in India, from Tamil Nadu to Maharashtra, with Surprising Winners and Losers, National Geographic, 27 Mar. 2019, www.nationalgeographic.com/environment/2019/02/india-single-useplastic-bans-maharashtra-tamil-nadu/. 
31. Sharma, Shivika, and Subhankar Chatterjee. "Microplastic Pollution, a Threat to Marine Ecosystem and Human Health: a Short Review." Environmental Science and Pollution Research, vol. 24, no. 27, 2017, pp. 21530-21547., doi:10.1007/s11356-017-9910-8.

32. Smith, Madeleine, et al. "Microplastics in Seafood and the Implications for Human Health." Current Environmental Health Reports, vol. 5, no. 3, 2018, pp. 375-386., doi:10.1007/s40572-018-0206-z.

33. Sonnenburg, Erica D., et al. "Diet-Induced Extinctions in the Gut Microbiota Compound over Generations." Nature, vol. 529, no. 7585, 14 Jan. 2016, pp. 212-215., doi:10.1038/nature16504.

34. Su, Lei, et al. "The Occurrence of Microplastic in Specific Organs in Commercially Caught Fishes from Coast and Estuary Area of East China." Journal of Hazardous Materials, vol. 365, 2019, pp. 716-724., doi:10.1016/j.jhazmat.2018.11.024.

35. Toussaint, Brigitte, et al. "Review of Micro- and Nanoplastic Contamination in the Food Chain." Food Additives \& Contaminants: Part A, vol. 36, no. 5, 2019, pp. 639-673., doi:10.1080/19440049.2019.1583381.

36. U.S. Environmental Protection Agency. "Learn about Polychlorinated Biphenyls (PCBs)." EPA, Environmental Protection Agency, 6 Feb. 2020, www.epa.gov/pcbs/learn-about-polychlorinated-biphenylspcbs\#healtheffects.

37. U.S. Environmental Protection Agency. "Plastics and Rubber Products Manufacturing (NAICS 326)." EPA, Environmental Protection Agency, 31 Mar. 2020, www.epa.gov/regulatory-information-sector/plastics-andrubber-products-manufacturing-naics-326.

38. "U.S. Energy Information Administration - EIA - Independent Statistics and Analysis." How Much Oil Is Used to Make Plastic? - FAQ - U.S. Energy Information Administration (EIA), www.eia.gov/tools/faqs/faq.php?id=34\&amp;t=6.

39. Yang, Chun Z., et al. "Most Plastic Products Release Estrogenic Chemicals: A Potential Health Problem That Can Be Solved." Environmental Health Perspectives, vol. 119, no. 7, 2011, pp. 989-996., doi:10.1289/ehp.1003220.

40. Department of Health, State of Washington. "Health Benefits of Fish." Washington State Department of Health, www.doh.wa.gov/CommunityandEnvironment/Food/Fish/HealthBenefits 


\section{Visual Sources:}

41. Bollendorff, Samuel. "Microplastics Sample Taken from the Great Pacific Garbage Patch at $34^{\circ} 42^{\prime} 210 \mathrm{~N}$ 142²1'004 W." OpenEdition, 2019, journals.openedition.org/factsreports/docannexe/image/5290/img2.jpg.

42. Gunther , Tim. "Marine Food Pyramid ." National Geographic, 2018, www.nationalgeographic.org/photo/marine-food-pyramid-1/.

43. US, Energy Information Administration. "Crude Oil Distillation Unit and Products." U.S. Energy Information Administration, 5 July 2012, www.eia.gov/todayinenergy/detail.php?id=6970.

44. Encyclopedia Britannica. "The Brahmaputra and Ganges River Basins and Their Drainage Network." Encyclopedia Britannica, www.britannica.com/place/Ganges-River. 